\title{
A decision support model to improve water resources management in agriculture: evaluation of the drip irrigation efficiency in the Ait Ben Yacoub region, East of Morocco
}

\author{
Ihssan Elouadi $^{1,2 *}$, Driss Ouazar ${ }^{1}$, and Lahcen El Youssfi ${ }^{3}$
}

\begin{abstract}
${ }^{1}$ Mohammadia School of Engineering, Mohamed V University, Rabat, Morocco; elouadihssan@gmail.com
${ }^{2}$ High National School of Mines of Rabat, Morocco 3Agronomy and Veterinary Medicine, Institute Hassan II, Rabat, Morocco

${ }^{3}$ Research team of environment and natural resources management, B2DRN Laboratory, Khenifra Higher School of Technology, Sultan Moulay Slimane University, Morocco
\end{abstract}

\begin{abstract}
Globally, climate change is projected to exacerbate water scarcity and increase the recurrence and intensity of droughts. These circumstances call for methodologies that can support the design of sustainable water management policies. Improved irrigation efficiency has been cited as an important way to adapt to climate change. This paper illustrates the potential of hydro-economic modeling for integrating the multiple dimensions of water resources, becoming a valuable tool in the empowerment of sustainable water management policies. The modelling framework is used also to analyze the impacts of climate change-induced drought on water uses in the Ait Ben Yacoub region (the East of Morocco). The evaluation of the conversion process from flurrow irrigation systems into drip irrigation by using the model showed that this policy has some positive effects on the agricultural gross margin and contributes to slightly moderating the impact of climate change on farmer's incomes. Moreover, aoptimal efficiency of drip irrigation will inevitably result in a decrease in the volume of infiltrated water and therefore a very likely drawdown of the groundwater level. This result demonstrates the limitation of this policy and the necessity to accompany this irrigation system by measures of improvement of water supply. It concerns rainwater storage basins that should be covered by the polyethylene geo-membrane as example of promising measures.
\end{abstract}

\section{Context and objectives}

Along the last decades, recent research on climate change has approached the assessment of impacts, vulnerability and adaptation under biophysical component focusing on one specific dimension of climate change, such as the agronomic dimension $[1,8]$, or the hydrological dimension $[9,10]$. However, the recognition of water management and climate change as multidimensional and multi-scalar concerns $[11,12]$ evidence the need to integrate biophysical, hydraulic and social economic component.

In line with this, varied types of integrated modelling frameworks have been developed to address the different scales (from the crop to the river basin) and the different dimensions of climate change, water and agriculture (hydrological, agronomic, and socio-economic). However, these frameworks have not always represented the socioeconomic dimension of water use in sufficient detail and in some cases, they have undervalued the role of human response to climate impacts.

Trying to better represent economic issues, hydro economic modelling has been extensively used along the last decades as a prominent tool for guiding and implementing water policy decisions $[13,17]$.

Along this line, this paper presents a novel application of a hydro- economic modelling framework that is used to assess climate change impacts and adaptation in the Ait ben Yacoub region The novelty of the approach presented here lies in the capability of this integrated framework to take into consideration agronomic, economic and hydrologic processes that take place at different scales.

Using this integrated approach, this paper evaluates the impacts of a severe climate change scenario and simulates the effect of Drip Irrigation System as a Climate Change Adaptation Measure on Ait Ben Yacoub region.

*Corresponding author: elouadihssan@gmail.com 


\section{Water, agriculture and climate change in the "Ait Ben Yacoub" region}

In Morocco, a semi-arid Mediterranean country, water resources become increasingly scarce. This scarcity will become acute in the coming years due to: a reduction in water supply (as a result of climate change), and increase in water demand, accentuated by the population growth and the requirements of economic development. Agriculture is regarded as a strategic sector for the country's socioeconomic development. However, this sector faces challenges many; water management among others.

Therefore, Morocco will have to deal with the additional challenges of climate change that will require the adaptation of economic activities dependent on water resources, such as irrigated agriculture, to the new climatic conditions. Dealing with climate change will require a shift in water management and farming decisions towards more sustainable agricultural production and more efficient water allocation, distribution and use.

The study area named "Ait Ben Yacoub " is located in the east of Morocco and characterized by a semi-arid climate where water is a limiting factor, thus constituting an unfavorable condition for agriculture. Major sources of Irrigation water in this region is thewater from AinLaarais with a flow rate of up to 2451 / s and groundwater exploration through wells and boreholes dug by farmers. The study area has 17 watersheds.

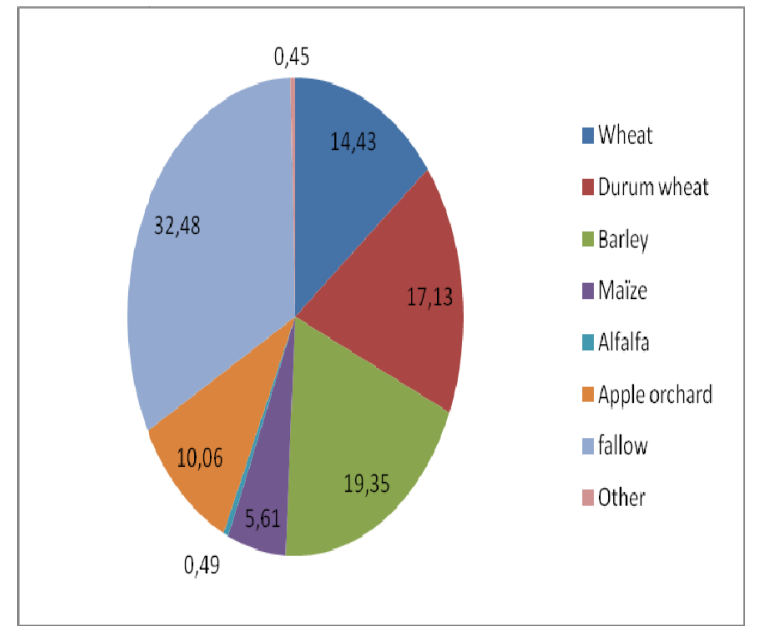

Fig.1:Ratios of crops types within the agricultural lands

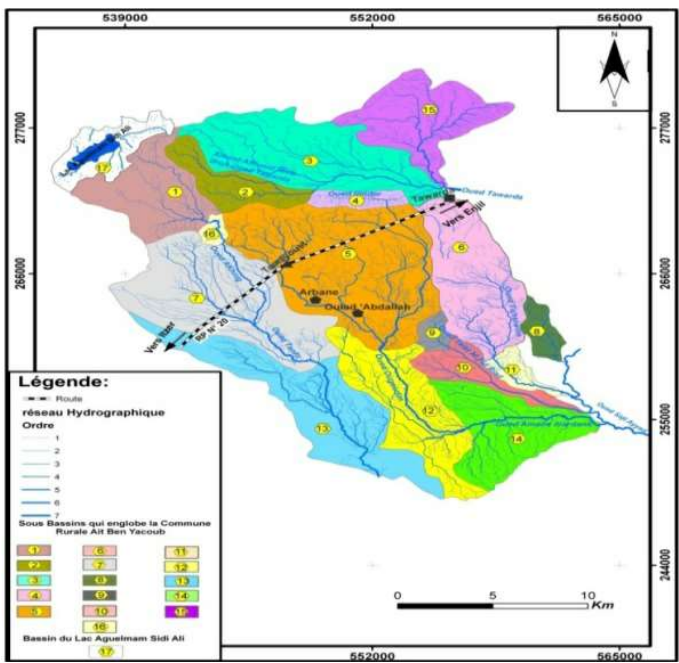

Fig.2: watersheds of Ait Ben Yacoub Region in Ait Ben Yacoub region

\section{Methodology: a hydro-economic modelling framework.}

To respond to the questions and challenges of climate change, we propose a hydro-economic modeling framework. The developedmodel integrates: economic, agronomic and hydraulic data. It can simulate the behavior of farmers faced with climate change and can takeinto account the competition for resources. 
The proposed approach is based on nonlinear optimization techniques. It's a hydrological and economic model that uses water resources so as to maximize the profit at the level of the basin while taking into account a set of constraints which are divided into hydrological, agricultural and resource availability constraints. As a major feature of this model of this model is a detailed disaggregation by spatial units (hydrological units, cropping areas, and grazing land), by agricultural production systems (irrigated and rainfed crops), and by farm sizes.

The Positive Mathematical Programming Method (PMP) approach, as suggested by Howitt [18], has been used to calibrate the models. The fundamental idea of PMP is to reconcile the new optimization of the mathematical programming model with the economic and social reality as evidenced in the database set. Essentially, PMP added calibration constraints so that the base solution is close to the database set. For reasons of computational simplicity and lacking strong arguments for other type of functions, a quadratic cost function is often employed (exceptions: [19, 20] ). The general version of this variable cost function to be specified is:

$\mathrm{Cv}=$ quadratic cost

$\mathrm{d}=(\mathrm{N} \times 1)$ vector of parameters associated with the linear term

$\mathrm{Q}=(\mathrm{N} \times \mathrm{N})$ symmetric, positive (semi-) definite matrix of parameters associated with the quadratic term.

However, the objective function of non-linear programming problem is composed of a quadratic cost calibrated using observed area of crop.

$$
\text { Max } Z=p x-d x-\frac{1}{2} Q x^{2}
$$

Subject to

$\begin{array}{ll}\text { Where } & A x \leq b[\lambda] \\ Z=\text { objective function value } & \\ \mathrm{p}=(\mathrm{N} \times 1) \text { vector of product prices } & \\ \mathrm{x} & =(\mathrm{N} \times 1) \text { vector of production activity levels } \\ \mathrm{A}=(\mathrm{M} \times \mathrm{N}) \text { matrix of coefficients in resource constraints } \mathrm{b}=(\mathrm{M} \times 1) \text { vector of available resource quantities } \\ \lambda=(\mathrm{M} \times 1) \text { vector of dual variables associated with the resource constraints. }\end{array}$

\section{Results and discussions}

\section{Simulation 1: climate change}

The model simulates the assessment of climate change impact on irrigated agriculture. This scenario provides insight on the behaviour of farmers in conditions of water scarcity. The impact of a reduction of $50 \%$ of water allocation, groundwater recharge and rainfall have been simulated at the basin level.

The results of this research show that climate change mayseverely impact irrigation systems in the Ait ben Yacoub region (figure 3). It will reduce considerably the availability of water resources, and willalso reduce also crop yields (between $2 \%$ and $10 \%$ ) and increase irrigation water requirements. The resulting changes of water stress, crop yields and crop competitiveness will drive changes of crop land allocations. The cultivated area will decrease significantly by $45 \%$ under drought conditions.

Model Results also demonstrate also that climate change will produce significant reductions of the region's income from 6.97 to 6.08 million USD. This reduction in the income concerns all types of farms but the small farms will be more vulnerable to climate change.

The model results highlight the remarkable impact of surface water management on the overexploitation of the groundwater and the risk of its excessivedepletion. A management policy of surface water based on administrative pricing, pumping cost, and water supply and marginal cost is proven inadequate for a sustainable resource management since it underestimates the overall water scarcity at the basin level (Fig. 1). The detailed results of this simulation are presented in the article [14]. 


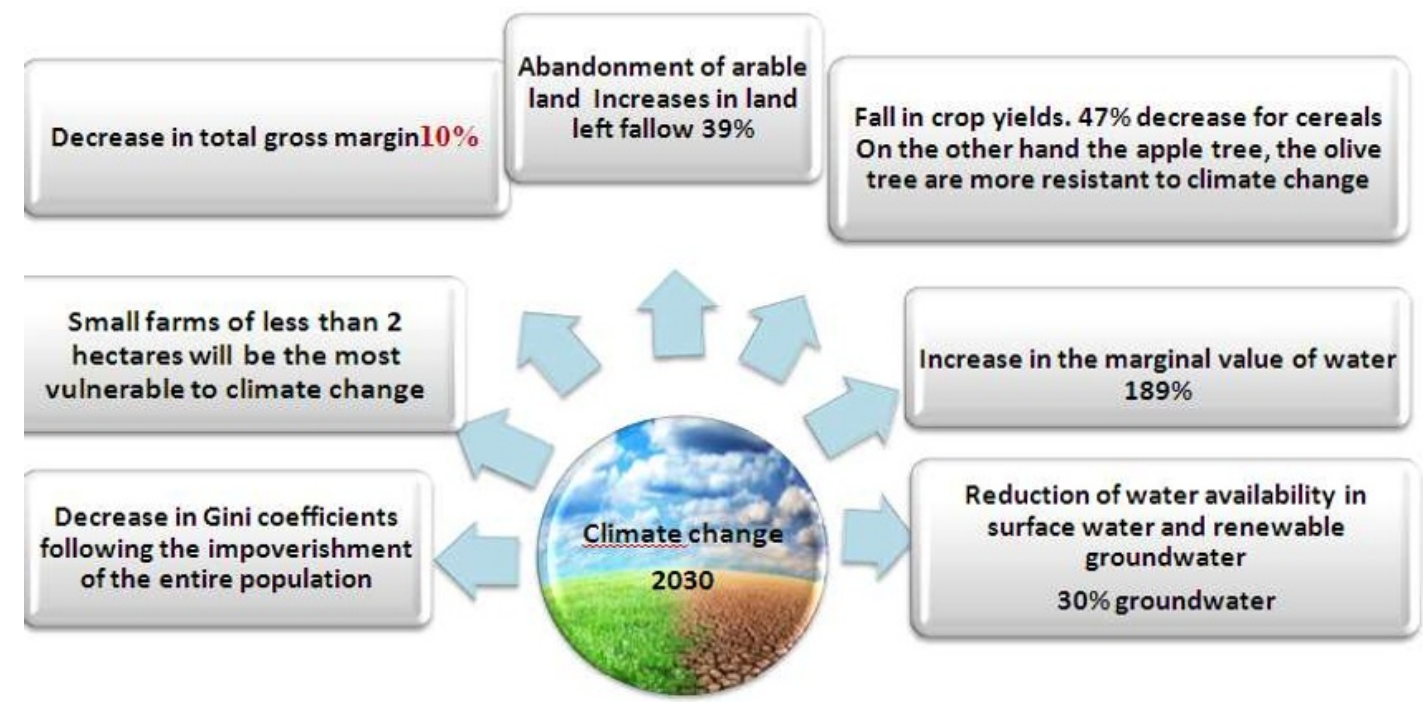

Fig.3: Model results simulation 1 - climate change impact

\section{Simulation 2: adaptation measures (drip irrigation)}

Climate change has introduced a number of pressing issues concerning water availability and predictability around the world. Old irrigation practices such as furrow irrigation and imprecise sprinkler irrigation are outdated and inefficient. Several researches have confirmed that the adoption of improved irrigation will be important for agricultural adaptation to climate change.

The model evaluates the effect of Drip Irrigation System Implementation as a Climate Change Adaptation Measure on Ait Ben Yacoub region. The evaluation of the conversion process from furrow irrigation systems into drip irrigation by using the model showed that, this adaptation measure will help to slightly reduce the negative effects of the drought in terms of profit. It has some positive effects on the agricultural gross margin and contributes to slightly moderate the impact of climate change on farmer's incomes.

The farmer will tend to gradually abandon cereal crops and alfalfa to grow crops with higher water value such as arboriculture. This change in rotation is not very spectacular for this simulation because it is slowed down by an acute water stress recorded on the scale of underground aquifers. Moreover, a better efficiency of drip irrigation will inevitably result in a decrease in the volume of infiltrated water and therefore a very likely drawdown of the groundwater level.

This result demonstrates the limitation of this policy and the necessity to support this irrigation system by measures of improvement in water supply. It concerns rainwater storage basins that should be covered by the polyethylene geomembrane as example of measures. The success of any agricultural adaptation strategy in the face of climate change is conditioned by the introduction of new crops resistant to new climatic hazards.

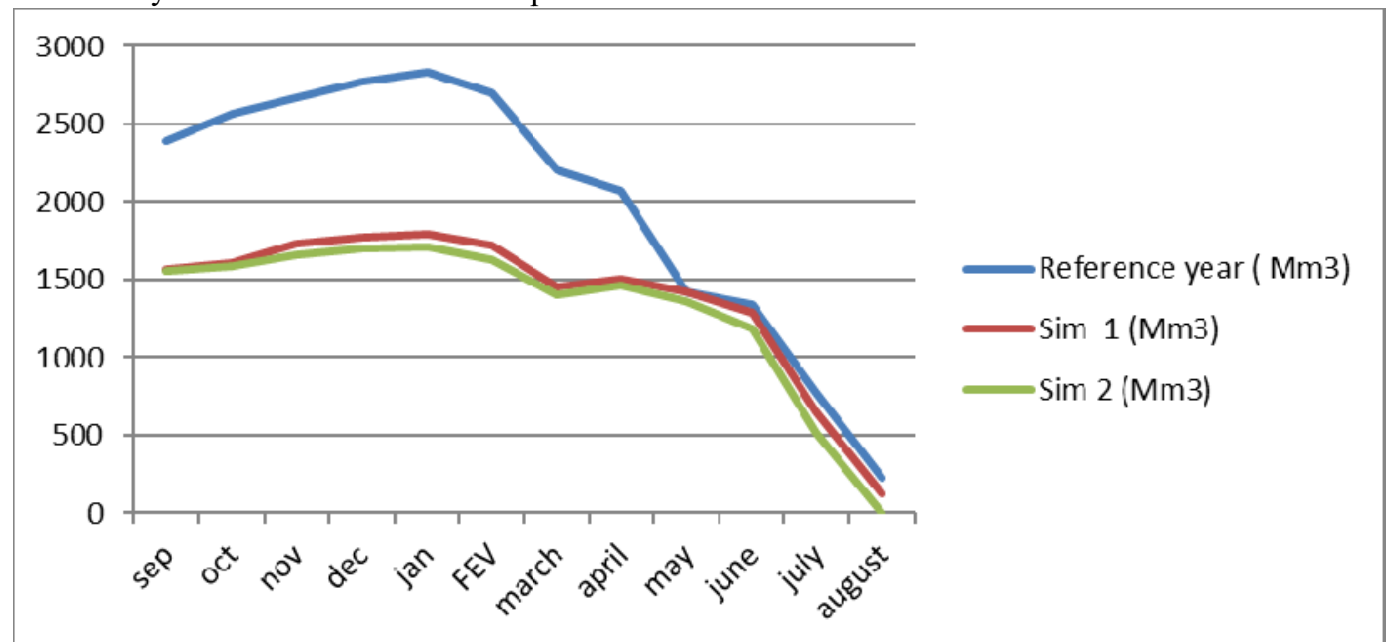

ig.4 : Evolution of the volume of water stored in "itzer-injel" aquifers in million $\mathrm{m}^{\text {s }}$ (reference Year and climate change scenario) 


\section{Conclusion}

Improved irrigation efficiency has been cited as an important way to adapt to climate change [1- 6]. This study tried to contribute to a list of studies that have focused on the role of climate in adoption of irrigation technology.

This study revealed that the policy of shifting to drip irrigation system has some positive effects on the agricultural gross margin and contributes in mitigating the impact of climate change on farmer's incomes. Moreover, an optimal efficiency of drip irrigation will inevitably result in a decrease in the volume of infiltrated water and therefore a very likely drawdown of the groundwater level. This result demonstrates the limitation of this policy and the necessity to support this irrigation system by measures of the improvement of water supply.

\section{References}

1. I. Burton, Adaptation to climate change and variability in the context of sustainable development, In: Climate Change and Development, L. Gómez Echeverri (Ed.). Yale School of Forestry and Environmental Studies and United Nations Development Programme (UNDP), New Haven, CT, and New York, pp. 153-173 (2000)

2. B. Smit, M.W. Skinner, Mit Adapt Strategies Glob Ch 7, (2012)

3. Kurukulasuriya, P. and S. Rosenthal. 2003. Climate Change and Agriculture: A Review of Impacts and Adaptations. Climate Change Series No. 91 (World Bank, Washington, D.C, 2002, 2003)

4. T. Cavagnaro, L. Jackson, K. Scow, Climate change: Challenges and solutions for California agricultural landscapes. White Paper CEC-500- 2005-189-SF. California Climate Change Center. www.energy.ca.gov/2005publications/CEC-500- 2005-189/CEC-500-2005-189-SF.PDF. Accessed June 14, 2016, (2006)

5. Jackson, L., F. Santos-Martin, A. Hollander, W. Horwath, R. Howitt, J. Kramer, A. O'Geen, B. Orlove, J. Six, S. Sokolow, D. Sumner, T. Tomich, and S. Wheeler., Potential for adaptation to climate change in an agricultural landscape in the Central Valley of California. Final Paper CEC-500-2009-044-F. California Climate Change Center. Available at www.energy.ca.gov/2009publications/CEC-500- 2009-044/CEC-5002009-044-F.PDF. Accessed June 14, 2016, (2009)

6. B. Joyce, V. Mehta, D. Purkey, L. Dale, M. Hanemann. Climate change impacts on water supply and agricultural water management in California's Western San Joaquin Valley, and potential adaptation strategies. Final Paper CEC- 500-2009-051-F. California Climate Change Center. Available at www.energy.ca.gov/2009publications/ CEC-500-2009-051/CEC-500-2009-051-F.PDF. (Accessed June 14, 2016), (2009)

7. M. Moriondo, M. Bindi, W. Zbigniew,W. Kundzewicz, M. Szwed, A. Chorynski, P. Matczak, M. Radziejewski,D. McEvoy, A.Wreford, Adapt. Strateg. Glob. Chang. 15 (2010)

8. D. Ventrella, M. Charfeddine, M. Moriondo, M. Rinaldi, M. Bindi, Reg. Environ. Chang. 12, (2012)

9. B.A. .Joyce, V.K. Mehta, D.R. Purkey, L.L. Dale, M. Hanemann, Clim. Chang. 109 (Suppl. 1), (2011)

10. S. Rochdane, B. Reichert, M. Messouli, A. Babqiqi, M.Y. Khebiza, Water 4, (2012)

11. T.E. Downing, WIREs Clim. Chang. 3, (2012)

12. H. Meinke, S.M. Howden, P.C. Struik, R. Nelson, D. Rodriguez, S.C. Chapman, Curr. Opin. Environ.Sustain. 1, (2009)

13. I. El ouadi, D. Ouazar, R. Doukkali, L. El Youssfi, International Journal of Education and Research, 2 (2014)

14. I. El ouadi, D. Ouazar, R.Doukkali, D. Hasnaoui, International Journal of Applied Engineering Research 12, (2018)

15. I. Blanco-Gutiérrez, C. Varela-Ortega, D.R. Purkey, J. Environ. Manag. 128, (2013)

16. Brouwer, R., Hofkes, M., Ecol. Econ. 66, (2008)

17. I. Heinz, M. M. Pulido-Velazquez, J.R. Lund, J. Andreu, Water Resour. Manag. 21, (2007)

18. R.E. Howitt, American Journal of Agricultural Economics, 77 (1995)

19. Q. Paris Q., and R.E. Howitt, American Journal of Agricultural Economics, 80 (1998)

20. Q. Paris Q., and R.E. Howitt, The Multi-Output and Multi-Input Symmetric Positive Equilibrium Problem. In: Heckelei, T., H.P. Witzke, and W. Henrichsmeyer (Eds.): Agricultural Sector Modelling and Policy Information Systems. Proceedings of the 65th EAAE Seminar, March 29-31, 2000 at Bonn University, VaukVerlag Kiel, (2001) 